\title{
HUBUNGAN PELAYANAN ANTENATAL CARE DENGAN KEPUTUSAN \\ PEMILIHAN PERTOLONGAN PERSALINAN DI DESA TAMBUNAN KECAMATAN SIBOLANGIT KABUPATEN DELI SERDANG TAHUN 2011
}

\author{
Efendi Sianturi \\ Jurusan Kebidanan Poltekkes Medan
}

\begin{abstract}
Abstrak
Masalah Kesehatan Ibu dan Anak (KIA) masih merupakan masalah kesehatan di Indonesia. Berbagai upaya telah dilakukan untuk mereduksi AKI di Indonesia, antara lain meningkatkan pertolongan persalinan oleh tenaga profesional dan yang menjadi ruang lingkup permasalahan dalam penelitian ini adalah "Bagaimana hubungan pelayanan antenatal care dengan keputusan pemilihan pertolongan persalinan di Desa Tambunan Kecamatan Sibolangit Kabupaten Deli Serdang Tahun 2011. "Jenis penelitian ini merupakan penelitian survey deskriptif analitik dengan menggunakan pendekatan desain cross sectional bertujuan mengetahui hubungan pelayanan antenatal care (ANC) dengan keputusan pemilihan pertolongan persalinan di Desa Tambunan Kecamatan Sibolangit Tahun 2011 dengan populasi adalah seluruh ibu bersalin di Desa Tambunan Kecamatan Sibolangit Kabupaten Deli Serdang yang berjumlah 64 orang. Hasil dalam penelitian ini adalah Pelayanan ANC mayoritas melaksananakan Pelayanan ANC sebanyak 49 orang $(76,6 \%)$ dan minoritas tidak melaksanakan ANC sebanyak 15 orang $(23,4 \%)$, pemilihan keputusan petolongan persalinan mayoritas melakukan pemilihan keputusan sebanyak 42 orang $(65,6 \%)$ dan minoritas tidak melakukan keputusan sebanyak 22 orang $(34,4 \%)$ dan terdapat hubungan pelayanan $\mathrm{ANC}$ dengan pemilihan keputusan pertolongan persalinan di Desa Tambunan Kecamatan Sibolangit Kabupaten Deli Serdang Tahun 2011. Kesimpulan dalam penelitian ini adalah diharapkan ibu untuk meningkatkan pemeriksaan kehamilan apabila mengalami kehamilan berikutnya, ibu yang tidak melakukan keputusan pemilihan sebaiknya melakukan keputusan pemilihan pertolongan persalinan terutama kepada tenaga kesehatan, bagi tenaga kesehatan diharapkan perlunya meningkatkan informasi tentang pentingnya pelayanan ANC bagi ibu melalui penyuluhan, bagi tempat penelitian diharapkan perlunya penyebaran informasi tentang pelayanan ANC dan keputusan pemilihan keputusan pertolongan persalinan dan bagi peneliti selanjutnya
\end{abstract} diharapkan untuk meneliti variabel lain yang lebih luas.

Kata Kunci : Pelayanan ANC, Keputusan Pemilihan Pertolongan Persalin

\section{PENDAHULUAN}

\section{Latar Belakang}

Masalah Kesehatan Ibu dan Anak (KIA) masih merupakan masalah kesehatan di Indonesia. Berbagai upaya telah dilakukan untuk mereduksi AKI di Indonesia, antara lain meningkatkan pelayanan antenatal di semua fasilitas pelayanan kesehatan dengan mutu yang baik serta menjangkau semua kelompok sasaran, meningkatkan pertolongan persalinan oleh tenaga profesional secara berangsur, meningkatkan deteksi dini risiko tinggi ibu hamil dan melaksanakan sistem rujukan serta meningkatkan pelayanan neonatal dengan mutu yang baik. Tujuan akhir dari Program KIA tersebut menurunkan angka kematian ibu dan anak (Profil Depkes RI 2010).

Salah satu tenaga kesehatan yang terlibat langsung terhadap pelayanan kesehatan ibu dan anak adalah bidan. Bidan mempunyai tugas penting dalam memberikan bimbingan, asuhan dan penyuluhan kepada ibu hamil, persalinan dengan tanggung jawabnya sendiri serta memberikan asuhan kepada bayi baru lahir. Asuhan ini termasuk tindakan pencegahan, deteksi kondisi abnormal pada ibu dan anak, serta melaksanakan tindakan kegawatdaruratan medik (Profil Depkes RI, 2010).

Hasil Survei Demografi dan Kesehatan (SDKI) tahun 2010-2011, angka kematian ibu mencapai 228/10.000 kelahiran hidup, hal ini berarti lebih dari 18.000 ibu meninggal per tahun atau 2 ibu meninggal tiap jam oleh sebab kehamilan, persalinan dan nifas. Bila dibandingkan dengan target yang hendak di capai pada tahun 2015 masih jauh dari yang diharapkan yaitu 102/100.000 kelahiran hidup. Untuk mewujudkan hal ini, Depkes sedang menggalakkan program Making Pregnancy Saver (MPS) dengan program yaitu Program Perencanaan Persalinan dan Pericegahan Komplikasi - P4K (Profil Depkes RI, 2010).

Hasil Survei Kesehatan Nasional (Susenas) tahun 2008, bahwa dari 320 wanita usia reproduksi tercatat 38 kematian maternal, $29 \%$ diantaranya terjadi saat hamil, $45 \%$ pada saat persalinan dan $26 \%$ pada masa nifas. 
Proporsi kematian maternal di pedesaan 3 kali lebih besar dari perkotaan. Berdasarkan cakupan pertolongan persalinan diketahui terdapat $31,2 \%$ ibu untuk pertolongan awal persalinan pergi ke tenaga non kesehatan (dukun $28,3 \%$, keluarga $2,4 \%$, lain-lain $0,5 \%$ ), dan penolong persalinan terbanyak adalah bidan $(64,5 \%)$ termasuk bidan swasta (Profil Depkes RI, 2010).

Diwilayah kota Medan, angka kematian ibu maternal (ibu hamil, ibu melahirkan dan ibu nifas) tahun 2007 yaitu 11 orang sedangkan kematian ibu maternal pada tahun 2008 mengalami peningkatan yaitu 13 orang. Sedangkan faktor peningkatan kematian ibu maternal ini, antara lain disebabkan oleh pendarahan akibat komplikasi dari kehamilan $(46,15 \%)$, eklamsia $(15,38 \%)$ dan sebab lain $(38,46 \%)$. AKI yang masih tinggi ini harus menjadi perhatian bagi Dinas Kesehatan Kota Medan dan pemantauan program yang ditujukan kepada ibu hamil, ibu melahirkan dan ibu nifas (Profil Dinkes Kota Medan, 2008).

Diwilayah Desa Tambunan Kecamatan Sibolangit Kabupaten Deli Serdang diketahui bahwa ibu bersalin melakukan pertolongan persalinan ke tenaga kesehatan sebanyak 42 orang dan yang melakukan pertolongan persalinan ke dukun sebanyak 22 orang. Hal ini menunjukkan bahwa masih rendahnya ibu dalam melakukan keputusan pertolongan persalinan. Ini membuktikan bahwa ibu hamil masih banyak melahirkan kepada dukun beranak. (http://www.medanbisnisdaily.com/mobile/read/? id $=37$ 269).

Dilihat dari proporsi tenaga bidan di Indonesia sebesar $34,8 \%$ per 10.000 penduduk, dengan jumlah bidan 30.236 orang yang ditempatkan di desa-desa seluruh Indonesia, dan masih ada $43,22 \%$ desa lagi yang belum tersedia bidan. Hal ini berarti bahwa di Indonesia masih membutuhkan tenaga profesional dalam memberikan pertolongan persalinan bagi ibu bersalin (Profil Depkes RI, 2010).

Pemanfaatan pertolongan persalinan oleh tenaga profesional (bidan) di masyarakat masih sangat rendah dibandingkan dengan indikator yang diharapkan. Hal ini dapat disebabkan oleh faktor ibu seperti kurangnya pemanfaatan pelayanan antenatal care pada saat kehamilan, kurangnya pemanfaatan ini dipengaruhi oleh jarak pelayanan kesehatan, bidan tidak berada ditempat dan biaya (Faiza, 2010).

Di desa Tambunan Kecamatan Sibolangit Kabupaten Deli Serdang yang mempunyai cakupan pertolongan persalinan terendah dibanding desa Sembahe Kecamatan Sibolangit Kabupaten Deli Serdang. Hal ini disebabkan oleh belum maksimalnya kunjungan pelayanan antenatal care.

Pemeriksaan kehamilan begitu penting dan wajib dilakukan oleh para ibu hamil, karena dalam pemeriksaan tersebut dilakukan monitoring secara menyeluruh baik mengenai kondisi ibu maupun janin yang sedang dikandungnya. Dengan pemeriksaan kehamilan kita dapat mengetahui perkembangan kehamilan, tingkat kesehatan kandungan, kondisi janin, dan bahkan penyakit atau kelainan pada kandungan yang diharapkan dapat dilakukan penanganan secara dini.

Menurut Depkes RI (2010) tujuan ANC adalah untuk menjaga agar ibu hamil dapat melalui masa kehamilannya, persalinan dan nifas dengan baik dan selamat, serta menghasilkan bayi yang sehat. Sedangkan menurut Rustam Muchtar (2005) bertujuan untuk menyiapkan seoptimal mungkin fisik dan mental ibu dan anak selama dalam kehamilan, persalinan, dan nifas, sehingga didapatkan ibu dan anak yang sehat dan mengurangi Angka Kematian Ibu (AKI). Dengan pemanfaatan pelayanan antenatal care akan mengetahui keadaan janin sehingga bisa mengambil keputusan untuk memanfaatkan tenaga ahli dalam pertolongan persalinan.

Menurut Sarwono (2004) yang mengutip pendapat Andersen dengan teorinya "Andersen's Behavioral model of Health Service Utilization", mengemukakan bahwa keputusan untuk menggunakan pelayanan kesehatan itu ada tiga komponen, yaitu (1) komponen predisposisi terdiri dari demografi, struktur sosial dan kepercayaan kesehatan, (2) komponen enabling (pendukung) terdiri dari sumber daya keluarga (penghasilan keluarga, kemampuan membeli jasa pelayanan dan keikutsertaan dalam asuransi kesehatan), dan sumber daya masyarakat (jumlah sarana pelayanan kesehatan, jumlah tenaga kesehatan, rasio penduduk dan tenaga kesehatan, lokasi sarana kesehatan), (3) komponen need, merupakan komponen yang paling langsung berpengaruh terhadap pelayanan kesehatan. Berdasarkan analisis teori tersebut, maka dapat disimpulkan determinan keputusan ibu hamil untuk melakukan pertolongan persalinan dipengaruhi oleh kunjungan pemeriksaan kehamilan.

Target pencapaian kegiatan ANC menurut Depkes RI (2008) K1 sebesar 92,9\% dan tahun 2010 sebesar 95\%. Pencapaian program K1 untuk Kabupaten Deli Serdang masih jauh dengan target yaitu sebesar $88.47 \%$, untuk K4 sebesar $86,98 \%$. Dengan demikian hasil pencapaian cakupan K4 masih perlu ditingkatkan seoptimal mungkin sehingga target pencapaian kegiatan 2010 sebesar 95\% untuk K1 maupun K4 dapat diwujudkan (Profil Dinkes Deli Serdang, 2010).

Demikian juga dengan kunjungan pemeriksaan kehamilan Puskesmas Pembantu Desa Tambunan Kecamatan Sibolangit tahun 2010 terdapat bahwa K1 sebesar $63,22 \%$ dan K4 sebesar $76,67 \%$. Pencapaian program sangat jauh dibandingkan target yang ditetapkan, dimana target nasional sebesar $95 \%$ tahun 2010. Dengan demikian hasil pencapaian cakupan program K1 dan K4 masih perlu ditingkatkan seoptimal mungkin sehingga target pencapaian kegiatan 2010 sebesar 95\% untuk K1 maupun K4 dapat diwujudkan (Profil Depkes, 2010).

Berdasarkan hasil survei awal yang dilakukan oleh peneliti, melalui wawancara kepada beberapa ibu bersalin yang berobat ke puskesmas, diketahui bahwa ada sebagian ibu hamil yang melakukan pertolongan persalinan pada dukun, dengan pertimbangan sewaktu hamil tidak 
memeriksakan kehamilannya ke tenaga kesehatan dan kurang mengetahui pentingnya pemeriksaan kehamilan dan pertolongan persalinan oleh bidan. Kemudian ibu hamil yang memilih pertolongan persalinan ke bidan dipengaruhi oleh sewaktu hamil rajin melakukan pemeriksaan kehamilan secara rutin ke bidan. Berdasarkan data yang diperoleh dari Puskesmas Pembantu Desa Tambunan Kecamatan Sibolangit pada umumnya ibu bersalin yang tidak melakukan pemeriksaan kehamilan oleh tenaga kesehatan mereka memilih pertolongan persalinan ke dukun.

Berdasarkan latar belakang tersebut di atas, maka penulis tertarik melakukan penelitian tentang hubungan pelayanan antenatal care dengan keputusan pemilihan pertolongan persalinan di Desa Tambunan Kecamatan Sibolangit Kabupaten Deli Serdang Tahun 2011.

\section{Rumusan Masalah}

Berdasarkan latar belakang di atas maka yang menjadi permasalahan dalam penelitian ini adalah "Bagaimana hubungan pelayanan antenatal care dengan keputusan pemilihan pertolongan persalinan di Desa Tambunan Kecamatan Sibolangit Kabupaten Deli Serdang Tahun 2011".

\section{Tujuan Penelitian}

Tujuan penelitian ini adalah untuk mengetahui hubungan pelayanan antenatal care dengan keputusan pemilihan pertolongan persalinan di Desa Tambunan Kecamatan Sibolangit Kabupaten Deli Serdang Tahun 2011.

\section{Manfaat Penelitian}

1. Memberikan masukan kepada Dinas Kesehatan Kabupaten Deli Serdang dalam penempatan tenaga bidan di daerah-daerah terpencil sehingga dapat diakses oleh masyarakat dalam pelayanan kesehatan ibu dan anak

2. Memberikan masukan kepada Puskesmas Pembantu desa Tambunan Kabupaten Deli Serdang tentang gambaran pemanfaatan pertolongan persalinan oleh tenaga bidan dalam peningkatan pelayanan antenatal bagi ibu hamil.

\section{Hipotesis Penelitian}

Hipotesis penelitian yaitu jawaban sementara penelitian, patokan duga atau dalil sementara yang kebenarannya akan dibuktikan dalam penelitian tersebut (Notoatmodjo, 2010).

Berdasarkan kerangka konsep teoritis dan dafenisi operasional dapat diajukan hipotesis sebagai berikut :

1. Hipotesis $\mathrm{Nol}(\mathrm{Ho})$

Tidak ada hubungan pelayanan antenatal care dengan keputusan pemilihan pertolongan persalinan di desa Tambunan Kecamatan Sibolangit Kabupaten Deli Serdang tahun 2011 dengan nilai $\mathrm{P}>0.05$.

2. Hipotesisi Alternatif $(\mathrm{Ha})$
Ada hubungan pelayanan antenatal care dengan keputusan pemilihan pertolongan persalinan di desa Tambunan Kecamatan Sibolangit Kabupaten Deli Serdang tahun 2011 dengan nilai $\mathrm{P}<0.05$.

\section{METODE PENELITIAN}

Jenis penelitian ini merupakan penelitian survey deskriptif analitik dengan menggunakan pendekatan desain cross sectional yang dilakukan di Desa Tambunan Kecamatan Sibolangit Kabupaten Deli Serdang yang telah dilaksanakan pada bulan Desember Tahun 2011.

Populasi dalam penelitian ini adalah seluruh ibu bersalin di Desa Tambunan Kecamatan Sibolangit Kabupaten Deli Serdang sebanyak 64 orang dan seluruhnya dijadikan sebagai sampel penelitian (total sampling). Variabel yang diteliti adalah pelayanan ANC sebagai variabel bebas dan keputusan pemilihan pertolongan persalinan sebagai variabel terikat.

Pengumupulan data dilakukan dengan menggunakan kuesioner terhadap ibu bersalin berupa: umur ibu, paritas, pendidikan, pekerjaan, pelayanan ANC dan keputusan pemilihan pertolongan persalinan.

\section{Pengolahan dan Analisa Data}

Pengolahan dan analisis data dilakukan dengan editing, coding, cleaning dan entry data dengan menggunakan SPSS for windows. Data diolah dan di analisa dengan dua tahap yaitu analisis univariat dan analisis bivariat. Analisis univariat dilakukan untuk menggambarkan karakteristik masing-masing variabel, yang disajikan dalam bentuk tabel distribusi frekuensi. Sedangkan analisi bivariat dilakukan untuk melihat ada tidaknya hubungan antara variabel bebas (pelayanan ANC) dan variabel terikat (keputusan pemilihan pertolongan persalinan) dengan menggunakan uji statistik Chi Square dengan $\alpha=0,05$ (Budiarto, 2001).

\section{HASIL PENELITIAN DAN PEMBAHASAN}

\section{Gambaran Úmum Lokasi Penelitian}

Secara geografis, desa Tambunan terletak di Kecamatan Sibolangit Kabupaten Deli Serdang yang berbatasan dengan :

a. Sebelah Utara, berbatasan dengan Sibolangit.

b. Sebelah Selatan, berbatasan dengan Pancur Batu.

c. Sebelah Timur, berbatasan dengan Kuta Limbaru.

d. Sebelah Barat, berbatasan dengan Sembahe.

Sedangkan secara demografis desa Tambunan Kecamatan Sibolangit Kabupaten Deli Serdang Tahun 2011 memiliki jumlah penduduk sebanyak 890 jiwa yang terdiri dari $124 \mathrm{KK}$ (Kepala Kelurga), laki-laki 386 jiwa dan perempuan 504 jiwa

\footnotetext{
Analisis Univariat

Setelah dilakukan pengumpulan, pengolahan dan analisis data, maka karakteristik responden yang
} 
diperoleh meliputi pelayanan ANC dan keputusan pemilihan pertolongan persalinan dapat dilihat pada tabel dibawah ini :

Tabel 3.1.Distribusi Frekuensi Pelayanan ANC di Desa Tambunan Kecamatan Sibolangit Kabupaten Deli Serdang Tahun 2011

\begin{tabular}{clcc}
\hline No & \multicolumn{1}{c}{ Pelayanan ANC } & Jumlah & $\%$ \\
\hline 1 & Melaksanakan ANC & 49 & 76,6 \\
2 & Tidak Melaksanakan ANC & 15 & 23,4 \\
\hline \multicolumn{2}{c}{ Total } & 64 & 100 \\
\hline
\end{tabular}

Tabel diatas terlihat bahwa mayoritas ibu hamil melaksanakan ANC yaitu 49 orang $(76,6 \%)$ dan sebanyak 15 orang $(23,4 \%)$ tidak melaksanakan ANC

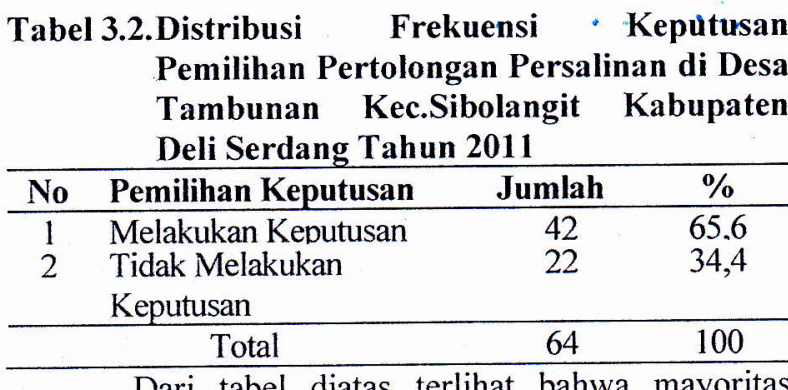

Dari tabel diatas terlihat bahwa mayoritas melakukan keputusan 42 orang $(65,6 \%)$ dan minoritas tidak melakukan keputusan sebanyak 22 orang orang $(34,4 \%)$.

\section{Analisis Bivariat}

Untuk melihat hubungan pelayanan ANC dengan keputusan pemilihan pertolongan persalinan dilakukan dengan uji sitatistik Chi-Square dan dapat dilihat pada tabel dibawah ini:

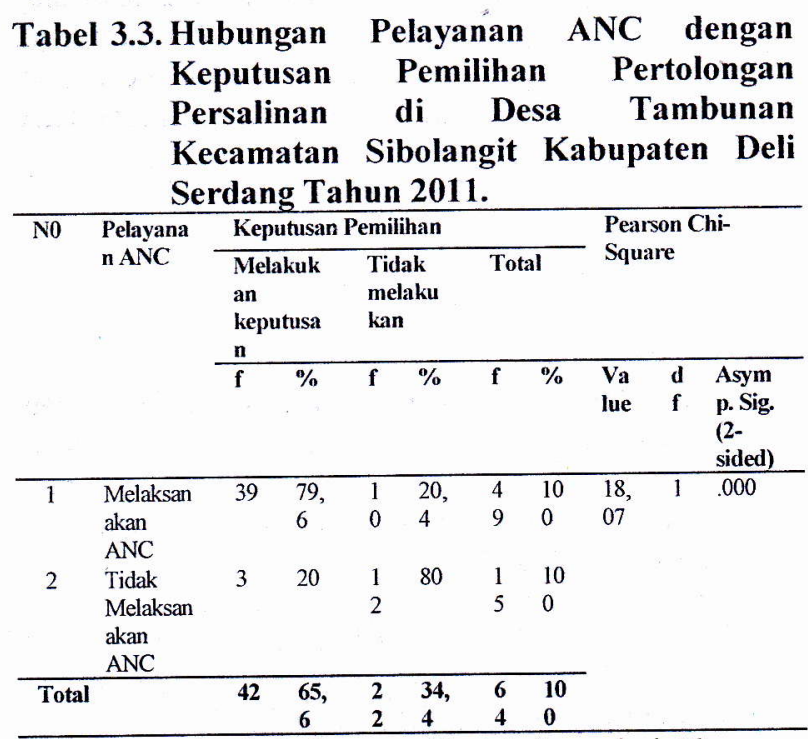

Dari tabel diatas terlihat bahwa dari 49 orang yang melaksanakan ANC terdapat 39 orang $(79,6 \%)$ yang melakukan keputusan dan 10 orang $(20,4 \%)$ yang tidak melakukan keputusan. Dari 15 orang yang tidak melaksanakan ANC terdapat 3 orang $(20 \%)$ yang melakukan keputusan dan 12 orang $(80 \%)$ yang tidak melakukan keputusan.
Kemudian berdasarkan hasil analisa statistik dengan uji chi-square terdapat Probabilitas $(0,000)<\alpha$ $(0,05)$ berarti Ho ditolak artinya terdapat hubungan pelayanan ANC dengan keputusan pemilihan pertolongan persalinan di Desa Tambunan Kecamatan Sibolangit Kabupaten Deli Serdang Tahun 2011.

\section{PEMBAHASAN}

\section{Pelayanan ANC}

Pelayanan ANC di Desa Tambunan mayoritas melaksanakan pelayanan ANC yaitu sebanyak 49 orang $(76,6 \%)$ dan minoritas tidak melaksanakan ANC sebanyak 15 orang $(23,4 \%)$. Berdasarkan hasil penelitian ini, pelayanan ANC masih tergolong rendah karena hanya mencapai $76,6 \%$ dan menunjukkan pencapaian program sangat jauh dibandingkan target yang ditetapkan, dimana target nasional sebesar $95 \%$ tahun 2010.

Menurut asumsi peneliti, pencapaian cakupan pelayanan ANC masih perlu ditingkatkan seoptimal mungkin sehingga target pencapaian pelayanan ANC sebesar 95\% dari seluruh kehamilan dapat tercapai dan perlu peningkatan pengetahuan dari ibu tentang manfaat dan kegunaan pelayanan ANC, karena dengan ANC ibu dapat memantau pertumbuhan dan perkembangan janin yang sedang dikandungnya. Peningkatan pengetahuan ini melalui penyuluhan dan pemberian informasi tentang manfaat pelayanan ANC dari tenaga kesehatan yang ada di desa Tambunan Kecamatan Sibolangit Kabupaten Deli Serdang.

Ibu yang melaksanakan pelayanan ANC dipengaruhi oleh pengetahuan yang dimiliki ibu tentang perlunya pemeriksaan kehamilan yang dikandungnya dan menganggap bahwa sangat penting untuk melakukan pemeriksaan kehamilan, karena dengan pemeriksaan kehamilan akan memantau perkembangan janin yang ada dikandungannya dan agar ibu tidak mengalami masalah-masalah dalam kehamilan.

Sedangkan ibu yang tidak melakukan pemeriksaan kehamilan mungkin dipengaruhi oleh berbagai faktor, namun menurut peneliti bahwa ibu yang tidak melakukan pemeriksaan kehamilan terhadap kandungannya disebabkan karena kurangnya pengetahuan dan kepedulian tentang kondisi kehamilannya sehingga tidak memanfaatkan pelayanan ANC dan mereka masih lebih percaya kepada dukun beranak untuk memeriksakan kehamilannya, untuk itu perlu peningkatan pengetahuan ibu tentang pentingnya pemeriksaan kehamilan khususnya ke tenaga kesehatan untuk memantau perkembangan janin yang sedang dikandungnya.

\section{Keputusan Pemilihan Pertolongan Persalinan}

Ibu bersalin yang berada di Desa Tambunan melakukan keputusan sebanyak 42 orang $(65,6 \%)$ dan tidak melakukan keputusan sebanyak 22 orang $(34,4 \%)$. Hal ini menunjukkan bahwa masih rendahnya keinginan ibu bersalin untuk melakukan keputusan 
pertolongan persalinan. Ini membuktikan bahwa ibu hamil masih banyak melahirkan kepada dukun beranak.

Menurut Robbins (2001), pengambilan keputusan yang optimal adalah rasional. Artinya, dia membuat pilihan memaksimalkan nilai yang konsisten dalam batasbatas tertentu.

Berdasarkan teori pengambilan keputusan, maka relevansinya dengan pengambilan keputusan pada ibu hamil terhadap pemilihan pertolongan persalinan didasari pada beberapa faktor-foktor pengambilan keputusan, antara lain berdasarkan pemikiran yang rasional, berdasarkan perasaan yaitu suatu proses tak sadar yang diciptakan dari dalam pengalaman yang tersaring, berdasarkan pilihan yang ada yaitu adanya pertimbanganpertimbangan membuat pilihan alternatif lain setelah mengaji untung ruginya, berdasarkan perbedaan budaya yaitu adanya perbedaan latar belakang budaya yang dianutnya sehingga keputusan yang diambil didasari oleh norma, kaedah dan adat istiadat yang ada.

Menurut asumsi peneliti masih banyak ibu yang tidak datang ke tenaga kesehatan khususnya bidan, hal ini perlu peningkatan pengetahuan bahwa saat bersalin sebaiknya yang membantu persalinannya adalah tenaga kesehatan. Peningkatan pengetahuan ini melalui penyuluhan dan pemberian informasi tentang keputusan pemilihan pertolongan persalinan oleh tenaga kesehatan yang ada di desa Tambunan Kecamatan Sibolangit Kabupaten Deli Serdang.

Ibu yang melakukan keputusan pemilihan pertolongan persalinan sangat dipengaruhi oleh pengetahuan yang dimiliki oleh ibu tersebut beserta keluarga, mereka menganggap demi keselamatan ibu dan anak sewaktu melahirkan sebaiknya dibantu oleh tenaga kesehatan yang ada di Desa Tambunan khususnya bidan. Hal ini menunjukkan keputusan pertolongan persalinan yang diambil oleh ibu sudah tepat bahwa ibu datang bersalin ke tenaga kesehatan.

Ibu yang tidak melakukan keputusan pemilihan pertolongan persalinan kepada petugas kesehatan khususnya bidan adalah suatu keputusan yang tidak tepat karena untuk bersalin ibu masih lebih percaya dibantu oleh dukun beranak untuk menolong persalinannya, dimana ibu kurang tahu resiko yang mungkin terjadi pasa saat persalinan apabila tidak dibantu oleh tenaga kesehatan. Untuk itu perlu peningkatan pengetahuan kepada ibu agar melakukan keputusan pemilihan pertolongan persalinan ketenaga kesehatan apabila nantinya ibu tersebut kembali hamil sehingga ibu dan janin yang dikandungnya selamat saat proses persalinan.

\section{Hubungan Pelayanan ANC Dengan Keputusan Pemilihan Pertolongan Persalinan di Desa Tambunan Kecamatan Sibolangit Kabupaten Deli Serdang Tahun 2011.}

Dalam Pelayanan ANC, responden mayoritas melakukan keputusan pemilihan sebanyak 39 orang $(79,6 \%)$ dan minoritas tidak melakukan keputusan pemilihan sebanyak 10 orang $(20,4 \%)$. Sedangkan keputusan pemilihan, responden mayoritas tidak melakukan keputusan sebanyak 12 orang $(80 \%)$ dan minoritas melakukan pemilihan keputusan sebanyak 3 orang $(20 \%)$.

Kemudian dari 49 orang yang melaksanakan ANC terdapat 39 orang $(79,6 \%)$ yang melakukan keputusan dan 10 orang $(20,4 \%)$ orang yang tidak melakukan keputusan. Dari 15 orang yang tidak melaksanakan ANC terdapat 3 orang (20\%) yang melakukan keputusan dan 12 orang $(80 \%)$ yang tidak melakukan keputusan.

Berdasarkan hasil analisa statistik dengan uji chisquare terdapat bahwa Probabilitas $(0,000)<\alpha(0,05)$ berarti Ho ditolak artinya terdapat hubungan pelayanan ANC dengan keputusan pemilihan pertolongan persalinan di Desa Tambunan Kecamatan Sibolangit Kabupaten Deli Serdang Tahun 2011.

Hal ini sesuai menurut Manuaba (2006), bahwa pertolongan persalinan merupakan salah satu bagian dari pelayanan antenatal care. Dengan pemanfaatan pelayanan antenatal maka akan mempengaruhi ibu dalam mengambil keputusan pemilihan pertolongan persalinan. Pelayanan ANC merupakan asuhan yang diperoleh ibu selama masa kehamilan sampai pada proses persalinan. Setiap ibu harus melakukan pelayanan ANC yang baik untuk mendeteksi dini kemungkinan adanya komplikasi dalam kehamilan dan membantu ibu dalam melakukan keputusan pemilihan pertolongan persalinan.

Menurut asumsi peneliti, pelayanan ANC berhubungan dengan pemilihan keputusan. Semakin banyak pelayanan $\mathrm{ANC}$ yang didapat oleh responden maka kemungkinan besar semakin terlaksana pemilihan keputusan. Ibu hamil masih ada yang tidak melaksanakan pelayanan ANC untuk itu diharapkan kepada ibu untuk meningkatkan pemeriksaan kehamilan apabila ibu tersebut mengalami kehamilan berikutnya untuk memantau perkembangan janin dan kesehatan ibu. Pada ibu yang tidak memilih keputusan pertolongan persalinan sebaiknya melakukan keputusan pemilihan pertolongan persalinan terutama kepada tenaga kesehatan untuk meningkatkan kesehatan ibu.

\section{KESIMPULAN DAN SARAN}

\section{Kesimpulan}

1. Pelayanan ANC dengan keputusan pemilihan pertolongan persalinan mayoritas melaksanakan pelayanan ANC sebanyak 49 orang $(76,6 \%)$ dan minoritas tidak melaksanakan ANC sebanyak 15 orang $(23,4 \%)$.

2. Keputusan pemilihan pertolongan persalinan mayoritas melakukan keputusan sebanyak 42 orang $(65,6 \%)$ dan minoritas tidak melakukan keputusan sebanyak 22 orang $(34,4 \%)$.

3. Terdapat hubungan antara pelayanan ANC dengan keputusan pemilihan pertolongan persalinan di Desa Tambunan Kecamatan Sibolangit Kabupaten Deli Serdang Tahun 2011. 


\section{Saran}

1. Diharapkan kepada ibu agar melakukan pemeriksaan kehamilan untuk meningkatkan kesehatan ibu dan janin.

2. Pada ibu yang tidak memilih keputusan pertolongan persalinan sebaiknya melakukan keputusan pemilihan pertolongan persalinan terutama kepada tenaga kesehatan untuk meningkatkan kesehatan ibu.

3. Diharapkan perlunya peningkatkan informasi tentang pentingnya pelayanan ANC bagi ibu melalui penyuluhan.

\section{DAFTAR PUSTAKA}

Bowo Arief, 2008, Pengantar Manajemen; Pemecahan Masalah dan Pengambilan Keputusan, Univ. Mercu Buana, Jakarta.

Budiarto Eko, 2001, Biostatistik untuk Kedokteran dan Kesehatan Masyarakat, EGC, Jakarta.

Depkes RI, 2005, Rencana Strategis Departemen Kesehatan Republik Indonesia 20052009, Jakarta.

Dinas Kesehatan Kota Medan, 2008, Profil Kesehatan Kota Medan.

Efendy Rustam, 2004, Ilmu Kesehatan Masyarakat, EGC, Jakarta.
Gulardi Wiknjosastro, 2008, Asuhan Persalinan Normal; Asuhan Esensial, Pencegahan dan Penanggulangan Segera Komplikasi Persalinan dan Bayi baru Lahir, Depkes RI, Jakarta.

Hanafi Wiknjosastro, 2005, Ilmu Kebidanan, Yayasan Bina Pustaka, Yogyakarta.

Hardywinoto \& Setiabudi, 2007, Panduan Gerontologi; Tinjauan Dari Berbagai Aspek, Jakarta.

Henderson, 2006, Ilmu Kebidanan, EGC. Jakarta.

Manuaba I.B. G. 2006, Ilmu Kebidanan, Penyakit Kandungan dan KB untuk Pendidikan Bidan. EG C. Jakarta.

Muchtar Rustam, 2005, Obsteti dan Ginekologi, Jakarta.

Notoatmodjo, 2010, Metodologi Penelitian Kesehatan, Rineka Cipta, Jakarta.

Prawiroharjo Sarwono, 2005, Ilmu Kebidanan, Yayasan Bina Pustaka, Yogyakarta.

Riyanto Agus, 2010, Pengolahan dan Analisis Data Kesehatan, Nuha Medika, Yogyakarta.

Saifuddin, 2005, Buku Acuan Pelayanan Kesehatan Maternal dan Neonatal. Yayasan Bina Pustaka Pustaka Sarwono Prawirohardjo, Yogyakarta.

Salmah, M. 2006, Hubungan Pemanfaatan Bidan dengan Cakupan Program, Jakarta.

Sarwono, S. 2004, Sosiologi Kesehatan. Beberapa Konsep Beserta Aplikasiny 